\title{
O corpus combinado e a pesquisa nos Estudos da tradução baseados em corpora
}

The use of bidirectional parallel corpus within Corpus based translation studies

Silvana Maria de Jesus ${ }^{1}$

RESUMO: Este artigo aborda as relações de tradução de SAY/DIZER em textos ficcionais no par linguístico inglês-português. Adotando uma perspectiva empírica de observação de dados em corpus combinado, este trabalho aborda os tipos de corpora e suas características, detalhando o corpus combinado e os procedimentos metodológicos ao se utilizar de dois programas computacionais - WordSmith Tools e SPSS. O corpus combinado apresentado é composto de três romances originais em inglês e suas traduções para o português e três romances originais em português e suas traduções para o inglês, e faz parte do CORDIALL (Corpus Discursivo para Análises Linguísticas e Literárias) desenvolvido pelos pesquisadores do LETRA (Laboratório Experimental de Tradução) da Faculdade de Letras da UFMG. Os programas WordSmith Tools e SPSS (Statistical Package for the Social Sciences) são utilizados para a extração de dados quantitativos para a construção de um banco de dados. Os resultados apresentam os equivalentes possíveis de SAY/DIZER, segundo as ocorrências do corpus, detectando-se padrões distintos nas relações de tradução, conforme a direção, seja do inglês para o português ou do português para o inglês.

PALAVRAS-CHAVE: Estudos da tradução baseados em corpora. Corpus combinado. Relações de tradução. Linguística de Corpus.

\begin{abstract}
This work reports on a study developed at LETRA - Laboratory for Experimentation in Translation, Faculdade de Letras, UFMG. Building on corpus based translation studies, it examines equivalence relations between two verbs in the pair English-Portuguese, SAY/DIZER. Equivalence is looked at from an empirical perspective drawing on data gathered from translated and non-translated fiction in both languages and in both translation directions. Equivalence relations are studied applying Corpus Linguistics methodology for quantitative data analysis, using two software - WordSmith Tools and SPSS (Statistical Package for the Social Sciences) - and a bidirectional parallel corpus (comparable and parallel) compiled to that end. It investigates the originals and their translations to search and account for possible equivalents. Results point to different patterns of these verbs, relating to their functions and to equivalence relations.
\end{abstract}

KEYWORDS: Corpus based translation studies. Bidirectional parallel corpus. Equivalence relations. Corpus Linguistics.

\footnotetext{
1 Professora Doutora do Curso de Tradução do Instituto de Letras e Linguística (ILEEL) da Universidade Federal de Uberlândia (UFU).
} 


\section{Introdução}

O uso de corpora de textos traduzidos em pesquisas de tradução tem como base os trabalhos de Baker $(1993,1995,1996)$, que por sua vez, têm como base os trabalhos de Toury (1995) com sua proposta de Estudos descritivos da tradução. Baker introduziu uma terminologia para os tipos de corpus, que se tornou bastante difundida, embora tenha recebido críticas e reformulações. Os trabalhos de Baker também são importantes pela abordagem que propõem - a busca de universais de tradução - que se constituiu em importante marco inicial para a investigação dos textos traduzidos.

Este artigo não pretende fazer um histórico sobre a Linguística de Corpus, tampouco sobre os Estudos da Tradução baseados em corpora, assuntos sobre os quais o leitor encontrará ampla discussão em Berber-Sardinha (2004) e no periódico Cadernos de Tradução IX (TAGNIN, 2002), um número especial sobre Tradução e Corpora.

O objetivo deste trabalho é trazer uma discussão sobre a terminologia utilizada para os tipos de corpora e introduzir um tipo de corpus pouco utilizado, o corpus combinado; pretende-se ainda mostrar como os dados brutos (raw data) do corpus oferecem material de análise ao pesquisador, a partir dos quais análises mais refinadas podem ser desenvolvidas, bem como descrever os procedimentos metodológicos para a obtenção de dados, destacandose os recursos informáticos utilizados, especialmente os software WordSmith e SPSS.

Inicia-se, portanto, este artigo, com a discussão sobre os tipos de corpora e a definição de corpus combinado. Em seguida, descrevem-se os procedimentos metodológicos para a obtenção de dados do corpus através de programas computacionais, observando-se como é possível formular perguntas de pesquisa a partir destes dados brutos e como estas perguntas iniciais podem nortear o refinamento da análise. Por fim, para ilustrar a metodologia, desenvolve-se uma pequena análise das relações de tradução entre SAY e DIZER, a partir dos dados de um corpus combinado.

\section{Os diferentes tipos de corpora}

Desde os trabalhos seminais de Baker (1993, 1995, 1996), que marcaram o início da interface entre os Estudos da Tradução e a Linguística de Corpus, os tipos de corpora utilizados nas pesquisas têm se diversificado de forma a contemplar diversos aspectos da descrição e comparação de línguas. 
Inicialmente, foram definidos por Baker (1995:230) três tipos: i) corpora paralelos textos originais em língua A e suas traduções em língua B; ii) corpora multilíngues - textos não-traduzidos compilados a partir de critérios comuns, como por exemplo, o gênero do discurso, nas línguas A e B; iii) corpora comparáveis - textos originalmente produzidos em uma língua $\mathrm{A}$ e textos traduzidos para essa mesma língua $\mathrm{A}$, ou seja, um corpus monolíngue, formado de textos não-traduzidos e textos traduzidos.

O termo comparável, utilizado por Baker para se definir corpora de textos traduzidos e não-traduzidos, pode ser usado como um termo geral, no sentido comum de se comparar duas ou mais características, que podem ser textos traduzidos $\mathrm{x}$ não-traduzidos, língua $\mathrm{A} \mathrm{x}$ língua $\mathrm{B}$, ou ainda gêneros diferentes, como textos acadêmicos $\mathrm{x}$ textos midiáticos, o que pode gerar certa confusão terminológica. Nas pesquisas linguísticas, fora do âmbito da tradução, o termo é usado para se nomear um corpus bilíngue ou multilíngue de textos nãotraduzidos em que aspectos de diferentes línguas estão sendo comparados.

Nos Estudos da tradução, tem-se optado pelos termos corpus comparável bilíngue (ou multilíngue) e corpus comparável monolíngue para se distinguir entre a comparação de textos não-traduzidos em línguas diferentes e textos traduzidos e não-traduzidos em uma mesma língua, respectivamente (Olohan, 2004:34). Hansen e Teich (2001), em uma análise contrastiva do inglês e do alemão, utilizam os termos textos comparáveis monolíngues, para o corpus de textos traduzidos e não-traduzidos em alemão, textos paralelos, para o corpus de textos originais em inglês e textos traduzidos em alemão, e textos comparáveis multilíngues, para o corpus de textos não-traduzidos em inglês e em alemão.

Observam-se, ainda, os tipos de corpora citados por Ana Frankenberg-Garcia (2006), considerados pela autora como relevantes para os estudos da tradução: corpora comparáveis bilíngues, corpora comparáveis monolíngues, corpora paralelos unidirecionais e corpora paralelos bidirecionais. A nomenclatura dos tipos de corpora por si só não define as características e finalidades dos mesmos, sendo então explicitados pela autora.

Corpora comparáveis bilíngues são formados de um subcorpus de textos na língua $\mathrm{A}$ e um subcorpus de textos na língua $\mathrm{B}$, não-traduzidos, não-paralelos, semelhantes em gênero e função e podem ser usados para extração de terminologia e no dia-a-dia de tradutores. Corpora comparáveis monolíngues são formados de um subcorpus de textos não-traduzidos e um subcorpus de textos traduzidos, ambos em língua $\mathrm{A}$, não-paralelos, semelhantes em gênero e função e podem ser usados para se observarem as diferenças entre a linguagem 
traduzida e a não-traduzida e para estudos teóricos sobre a tradução. Corpora paralelos unidirecionais são formados de um subcorpus de textos originais em língua A e um subcorpus com os textos traduzidos para a língua $\mathrm{B}$, são paralelos e semelhantes em gênero e função e podem ser usados para a pesquisa de equivalentes tradutórios, como suporte para a criação de dicionários bilíngues e para a tradução automática. Corpora paralelos bidirecionais são corpora bastante complexos e merecem uma explicação mais detalhada.

Os corpora paralelos bidirecionais, segundo Frankenberg-Garcia (2006), são formados de quatro subcorpora que, combinados entre si, podem formar outros corpora. Os quatro subcorpora se compõem em: 1) textos originais na língua A e 2) as suas traduções para a língua B, 3) textos originais na língua B e 4) as suas traduções para a língua A.

A autora explica que estes corpora formam dois corpora comparáveis monolíngues (1 e 4, traduzidos e não traduzidos na língua $A$, e 2 e 3, traduzidos e não traduzidos na língua B) e dois corpora comparáveis bilíngues ( 1 e 3, não-traduzidos na língua A e não-traduzidos na língua $\mathrm{B}$, e 2 e 4, traduzidos na língua $\mathrm{A}$ e traduzidos na língua $\mathrm{B}$ ).

Este tipo de corpus é denominado por Vela e Hansen-Schirra (2006) de corpus combinado paralelo-comparável (combined parallel-comparable corpus), ou simplesmente, corpus combinado e apesar de sua complexidade tem-se mostrado mais produtivo para as pesquisas em tradução. Hansen (2002:20) utiliza o termo corpus comparável e paralelo (comparable and parallel corpus) e descreve dois tipos de corpus combinado: o bilíngue e o multilíngue (mais de duas línguas).

Um dos estudos pioneiros na utilização de um corpus combinado, embora o autor não tenha utilizado esta denominação, é o de Johansson (1998). O autor utiliza um corpus formado de textos originais em inglês e suas traduções para o norueguês e textos originais em norueguês e suas traduções para o inglês. Johansson sugere a utilização dos seguintes termos para a denominação dos diferentes tipos de corpora: i) corpora comparáveis bilíngues/multilingues ou corpora de textos originais comparáveis, ii) corpora de tradução ou corpora de textos originais e suas traduções, podendo ser bilíngue (original na língua A e tradução na língua B) ou multilingue (original na língua A e traduções nas línguas B, C, D), e iii) corpora comparáveis monolíngues ou corpora de textos originais e traduzidos na mesma língua. 
Observando-se as classificações apresentadas, nota-se que os corpora, que geralmente são formados por distintos subcorpora, são classificados segundo três aspectos: i) a(s) língua(s) envolvida(s), ii) o status do texto, e iii) a direcionalidade.

Em relação à língua, os corpora podem ser monolíngues (somente textos em língua A), bilíngues (textos em língua A e B), ou multilíngues (textos em língua, A, B, C... n).

O status classifica o texto na sua relação com outros textos, podendo ser considerado como original, tradução e texto não-traduzido. Destaca-se aqui que este status não se refere ao texto em si, mas à sua posição em relação a outro(s) texto(s) do corpus. Um texto será considerado como original se ele estiver em relação de tradução com outro(s) texto(s), formando assim um corpus paralelo bilíngue (ou multilíngue) com original e tradução (ou traduções). Este mesmo texto pode ser classificado como texto não-traduzido se ele estiver sendo analisado em relação a um texto na mesma língua que é um texto traduzido, formando assim, um corpus comparável monolíngue com texto(s) não-traduzido(s) em língua A e texto(s) traduzido(s) em língua A.

O termo original é visto por alguns teóricos, principalmente aqueles voltados para a interface entre os Estudos da tradução e os Estudos culturais, como inadequado, por pressupor aspectos relativos às questões de hierarquia. Entretanto, opta-se por utilizar os termos original/tradução para se destacar que são textos que estão em relação de tradução, sendo os termos texto traduzido/texto não-traduzido utilizados para se referir aos textos que não estão em relação de tradução entre si.

Aspectos discursivos também podem ser apontados no status, como tipo textual, registro ou gênero textual. O corpus pode ser compilado de forma a contrastar as características de um gênero textual em duas línguas ou de gêneros textuais diferentes em uma mesma língua.

$\mathrm{O}$ aspecto direcionalidade indica se a análise é feita apenas na direção da língua $\mathrm{A}$ para a língua B ou se ela considera também a direção inversa, ou seja, da língua B para a língua A. Pode, portanto, apresentar-se como unidirecional, quando, por exemplo, compara-se uma dada característica em textos originais na língua A e em suas traduções na língua B; ou bidirecional, quando esta análise é ampliada com a comparação desta mesma característica em textos originais na língua B e em textos traduzidos para a língua A, ou seja, quando se utiliza um corpus combinado. 
Estes tipos básicos podem ser combinados conforme as necessidades de pesquisa e, como não há ainda uma terminologia consagrada para cada aspecto, cabe ao pesquisador explicitar as diversas características do corpus utilizado.

Outros aspectos relacionados à tipologia de corpus, como modo (falado ou escrito), tempo (sincrônico ou diacrônico) e outros, são abordados por Berber Sardinha (2004:20). A título de ilustração de diferentes tipos de corpora, podem-se observar alguns corpora em desenvolvimento nos Estudos da tradução, como por exemplo, o TEC, o CORDIALL e o CroCo. ${ }^{2}$ Remete-se ainda o leitor ao trabalho de Dayrell $(2005: 48)$ para um levantamento de corpora existentes em português.

\section{O corpus combinado}

O corpus combinado apresentado nesse artigo foi usado por Jesus (2008), sendo parte do Projeto CORDIALL (Corpus discursivo para análises linguísticas e literárias, desenvolvido pelos pesquisadores do LETRA - Laboratório Experimental de Tradução da Faculdade de Letras da UFMG) ${ }^{3}$. É composto por doze romances, somando um total de 1.237.970 palavras. Caracteriza-se como um corpus combinado que, como foi dito, é composto de vários corpora básicos, cujas combinações permitem a composição de vários corpora de análise. Os quatro corpora básicos desta pesquisa são ${ }^{4}$ :

1- Corpus PO - para português original ou não-traduzido

2- Corpus IT - para inglês traduzido

3- Corpus IO - para inglês original ou não-traduzido

4- Corpus PT - para português traduzido

Neste corpus os subcorpora 1-2 e 3-4 são paralelos, ou seja, no subcorpus 2 temos as traduções dos textos que compõem o subcorpus 1 e no subcorpus 4 as traduções dos textos que compõem o subcorpus 3. Em outra combinação, os subcorpora 1-4 e 2-3 são comparáveis monolíngues, ou seja, são formados de textos traduzidos e não-traduzidos em português e em

\footnotetext{
${ }^{2}$ TEC ( http://www.monabaker.com/tsresources/TranslationalEnglishCorpus.htm ), CORDIALL ( http://letra.letras.ufmg.br/letra/index.xml ) e CroCo (http://fr46.uni-saarland.de/croco/index en.html ).

3 Site do LETRA - http://letra.letras.ufmg.br/letra/

${ }^{4}$ As siglas IO, IT, PO, PT foram utilizadas por Tagnin (2002a:203) na construção do corpus para o Projeto terminológico para tradutores. A opção de utilizá-las na presente pesquisa deve-se ao fato de que as siglas facilitam a visualização do tipo de corpus, destacando-se ainda que os textos não-traduzidos utilizados no corpus desta pesquisa são também os textos originais.
} 
inglês, respectivamente. Há ainda um corpus comparável bilíngue formado por 1-3, com textos não-traduzidos em português e inglês.

Os textos foram utilizados anteriormente por pesquisadores do LETRA, oferecendo, portanto, a vantagem de já se encontrarem digitalizados. A compilação do corpus obedeceu aos seguintes critérios: romances disponíveis no CORDIALL, no par linguístico portuguêsinglês, publicados no século XX. Foram selecionados três romances para cada um dos subcorpora. O Quadro 1 apresenta os dados bibliográficos de cada romance e os corpora que eles compõem. ${ }^{5}$

Quadro 1 - Dados bibliográficos dos romances do corpus combinado

\begin{tabular}{|c|c|c|c|c|c|}
\hline Corpora & Título & Sigla & Autor/Tradutor & $1^{a}$ edição & $\begin{array}{c}\text { Edição } \\
\text { utilizada }\end{array}$ \\
\hline \multirow{3}{*}{ IO } & $\begin{array}{l}\text { Point counter } \\
\text { point }\end{array}$ & PCP & Aldous Huxley & 1928 & 1994 \\
\hline & $\begin{array}{c}\text { Interview with the } \\
\text { vampire }\end{array}$ & IWV & Anne Rice & 1976 & 1997 \\
\hline & Beloved & BEL & Toni Morrison & 1987 & 1998 \\
\hline \multirow{3}{*}{ IT } & Macunaíma & MAC & E A Goodland & 1984 & 1984 \\
\hline & $\begin{array}{l}\text { Gabriela, clove } \\
\text { and cinammon }\end{array}$ & GAB & $\begin{array}{c}\text { James L Taylor e } \\
\text { William Grossman }\end{array}$ & 1962 & 1962 \\
\hline & $\begin{array}{l}\text { The hour of the } \\
\text { star }\end{array}$ & THS & Giovanni Pontiero & 1986 & 1992 \\
\hline \multirow{3}{*}{$\mathrm{PO}$} & $\begin{array}{c}\text { Macunaíma: } o \\
\text { herói sem caráter }\end{array}$ & MHS & Mário de Andrade & 1928 & 1980 \\
\hline & $\begin{array}{c}\text { Gabriela, cravo e } \\
\text { canela }\end{array}$ & $\mathrm{GCC}$ & Jorge Amado & 1958 & 1958 \\
\hline & A hora da estrela & AHE & Clarice Lispector & 1977 & 1998 \\
\hline \multirow{3}{*}{ PT } & Contraponto & $\mathrm{CPO}$ & Érico Veríssimo & 1934 & 1971 \\
\hline & $\begin{array}{c}\text { Entrevista com o } \\
\text { vampiro }\end{array}$ & $\mathrm{ECV}$ & Clarice Lispector & 1977 & 1996 \\
\hline & Amada & AMA & $\begin{array}{l}\text { Evelyn Kay } \\
\text { Massaro }\end{array}$ & 1987 & 1987 \\
\hline
\end{tabular}

\footnotetext{
5 Para maiores detalhes sobre os corpora, remete-se o leitor aos trabalhos de Assis (2004) para os romances Beloved e Amada; Jesus (2004) para os romances Point counter point e Contraponto; Bueno (2005) para os romances Macunaíma, o herói sem caráter e Macunaíma; Cançado (2005) para os romances Interview with the vampire e Entrevista com o vampiro; Morinaka (2005) para os romances Gabriela, cravo e canela e Gabriela, clove and cinammon; e Rodrigues (2005) para os romances $A$ hora da estrela e The hour of the star.
} 
Estes subcorpora podem ser combinados, segundo os objetivos de análise, formando outros corpora para a investigação de aspectos específicos:

i) corpus paralelo IO-PT - formado de textos originais em inglês (IO) e suas traduções para o português (PT)

ii) corpus paralelo PO-IT - formado de textos originais em português (PO) e suas traduções para o inglês (IT)

iii) corpus comparável monolíngue IO-IT- formado de textos não-traduzidos em inglês (IO) e textos traduzidos em inglês (IT)

iv) corpus comparável monolíngue $P O-P T$ - formado de textos não-traduzidos em português (PO) e textos traduzidos em português (PT)

v) corpus comparável bilíngue IO-PO - formado de textos não-traduzidos em inglês (IO) e textos não-traduzidos em português (PO)

Em relação aos três aspectos que são observados em um corpus, quais sejam, língua(s), status e direcionalidade, este corpus caracteriza-se como bilíngue, composto por textos do par linguístico português-inglês; combinado, ou seja, contendo textos em ambas as relações - traduzidos/não-traduzidos e traduzidos/originais; e bidirecional, visto que a análise pode ser feita tanto na direção do português para o inglês quanto do inglês para o português. A próxima seção apresenta os procedimentos metodológicos para obtenção dos dados com o uso de programas computacionais.

\section{Procedimentos metodológicos}

O trabalho com corpus exige do pesquisador o uso de ferramentas computacionais para a obtenção de dados quantitativos. Esta seção introduz dois programas que podem ser usados para análises linguísticas, e os procedimentos metodológicos utilizados, ilustrando como as perguntas de pesquisa vão sendo desenvolvidas concomitantemente com a análise do corpus. 


\subsection{O programa WordSmith Tools e os dados brutos}

Após a compilação do corpus da pesquisa, o tratamento do corpus é feito com a combinação de procedimentos manuais por parte do pesquisador e automáticos com a utilização de programas computacionais.

O software WordSmith Tools $^{6}$ tem sido bastante utilizado em pesquisas com corpus. Para maiores detalhes sobre o programa remeto o leitor a Jesus (2004), Berber Sardinha (2004), Alves e Morinaka (2004) e ao site do programa ${ }^{7}$.

Com a ferramenta WordList é possível obter os seguintes dados do corpus: i) o número total de vocábulos (types) e o número total de ocorrências (tokens) do corpus e também de cada romance e/ou subcorpus; e ii) o número de ocorrências das formas de SAY/DIZER no corpus. A partir das formas encontradas na lista de palavras fornecida pela ferramenta Wordlist, buscam-se todas as ocorrências de SAY/DIZER com a ferramenta Concord.

A ferramenta Concord permite a busca de todas as formas de SAY/DIZER colocandose como nódulo, que é a palavra de busca, a forma say*/said para SAY e disse*/diz*/diria*/diga*/digo/dito/ditas/dir-se-ia para DIZER. A definição das formas a serem utilizadas como nódulo foi feita através da observação das listas de palavras obtidas com a ferramenta WordList. O asterisco (*) indica ao programa que se deve buscar todas as palavras que iniciem pelas letras antes do asterisco, assim, no caso de say* o programa busca também as formas saying e says. No caso de DIZER, quando se usa disse* buscam também as formas disseram, dissemos e assim por diante. Neste processo, o programa busca também palavras que não são formas de SAY/DIZER, como por exemplo, dizimados para a forma diz*, sendo necessário checar as linhas de concordância e eliminar estes casos. Para se eliminar as linhas, utiliza-se o comando deletar e o botão ZAP.

A Tabela 1 apresenta os dados de cada subcorpora do corpus combinado.

\footnotetext{
${ }^{6}$ Uma outra opção é o programa AntConc, que não possui as mesmas funcionalidades, mas é de uso gratuito http://www.laurenceanthony.net/antconc index.html .

${ }^{7}$ Mike Scott's Web http://www.lexically.net/wordsmith/ .
} 
Tabela 1 - Dados dos quatro corpora básicos do corpus combinado

\begin{tabular}{l|l|l|l|l}
\hline & \multicolumn{1}{|c|}{ IO } & \multicolumn{1}{c}{ IT } & \multicolumn{1}{c}{ PO } & \multicolumn{1}{c}{ PT } \\
\hline Types & 29.392 & 22.594 & 26.336 & 40.434 \\
\hline Tokens & 402.525 & 234.599 & 203.504 & 397.342 \\
\hline $\begin{array}{l}\text { Total de ocorrências de } \\
\text { SAY/DIZER }\end{array}$ & 2.723 & 776 & 707 & 2.385 \\
\hline \% de SAY/DIZER x tokens & 0.67 & 0.33 & 0.34 & 0.60 \\
\hline
\end{tabular}

O tamanho do corpus é um aspecto bastante discutido na sua compilação (Olohan, 2004:45), com uma tendência, nos Estudos da tradução baseados em corpora, para o uso de corpora de mesmo tamanho (em relação ao número de textos ou de tokens). Entretanto, o corpus combinado aqui apresentado é formado de romances inteiros, originais e traduções, o que dificulta a padronização do tamanho. Além disso, serão analisadas 150 ocorrências de cada subcorpus, não sendo, portanto, relevante a questão do tamanho do corpus.

Os dados brutos já permitem algumas considerações para análise:

i) corpus comparável bilíngue IO-PO

Há 2.723 ocorrências de SAY em IO e 707 ocorrências de DIZER em PO.

Logo, a ocorrência de SAY em textos não-traduzidos (IO) é significativamente maior do que a ocorrência de DIZER em textos não-traduzidos (PO); SAY representa $0.67 \%$ de tokens, ao passo que DIZER representa $0.34 \%$;

ii) corpus paralelo IO-PT

Há 2723 ocorrências de SAY em IO e 2.385 ocorrências de DIZER em PT.

Logo, a ocorrência de SAY nos textos originais é maior do que a de DIZER nos textos traduzidos. SAY equivale a $0.67 \%$ de tokens dos textos originais, enquanto que nas traduções a ocorrência de DIZER é de $0.60 \%$.

iii) corpus paralelo PO-IT

Há 707 ocorrências de DIZER em PO e 776 ocorrências de DIZER em IT.

Logo, a ocorrência de DIZER nos textos originais é semelhante à ocorrência de SAY nos textos traduzidos. DIZER equivale a $0.34 \%$ de tokens dos textos originais enquanto que nas traduções a ocorrência de SAY é de $0.33 \%$. Nota-se que a diferença é mínima em termos percentuais, ao passo que, em termos de ocorrências, o texto traduzido tem mais ocorrências 
de SAY do que os originais têm de DIZER. Nota-se que a ocorrência de SAY é maior do que a ocorrência de DIZER tanto no corpus comparável bilíngue (IO-PO) quanto nos corpora paralelos (PO-IT e IO-PT);

iv) corpus comparável monolíngue (IO-IT)

Há 2.723 ocorrências de SAY nos textos não-traduzidos (IO) e 776 ocorrências de SAY nos textos traduzidos (IT). SAY equivale a $0.67 \%$ de tokens dos textos não-traduzidos, enquanto que nas traduções a ocorrência é de $0.33 \%$. Nota-se, portanto, que a ocorrência de SAY nas traduções é significativamente menor do que a ocorrência em textos não-traduzidos.

v) corpus comparável monolíngue (PO-PT)

Há 707 ocorrências de DIZER nos textos não-traduzidos (PO) e 2.385 ocorrências de DIZER nos textos traduzidos (PT). DIZER equivale a $0.34 \%$ de tokens dos textos nãotraduzidos, enquanto que nas traduções a ocorrência é de $0.60 \%$. Nota-se, portanto, que a ocorrência de DIZER nas traduções é significativamente maior do que a ocorrência em textos não-traduzidos.

Estas considerações iniciais, obtidas através da observação dos dados brutos do corpus, permitem a elaboração de perguntas de pesquisas que orientarão a análise qualitativa do corpus. Cada um dos subcorpora do corpus combinado permite a análise de distintos aspectos das relações entre os textos que, somadas, contribuem para uma compreensão mais abrangente das relações de tradução. Estas perguntas baseiam-se no modelo de análise proposto por Teich (2003):

1- Qual a relação entre as orações verbais realizadas por SAY em textos ficcionais não-traduzidos em inglês e orações verbais realizadas por DIZER em textos ficcionais não-traduzidos em português?

2- As orações verbais realizadas por SAY são frequentemente traduzidas por orações verbais realizadas por DIZER e vice-versa? Qual a probabilidade de equivalência entre SAY/DIZER? Quais os outros itens lexicais em relação tradutória com SAY/DIZER? É possível estabelecer padrões que condicionem as relações de tradução? 
3- Qual a relação entre as orações verbais realizadas por SAY/DIZER em textos nãotraduzidos e as orações verbais realizadas por SAY/DIZER em textos traduzidos? Os textos traduzidos apresentam os mesmos padrões dos textos não-traduzidos ou estes padrões são condicionados pela relação dos textos traduzidos com os textos originais?

Para a investigação de cada pergunta, focaliza-se uma combinação diferente do corpus: 1- relações entre textos não-traduzidos em português e inglês (IO-PO); 2- relações entre textos traduzidos e textos não-traduzidos em inglês (IO-IT); 3- relações entre textos traduzidos e textos não-traduzidos em português (PO-PT); 4- relações entre textos originais em inglês e suas traduções para o português (IO-PT); e 5- relações entre textos originais em português e suas traduções para o inglês (PO-IT).

\subsection{O programa SPSS e o banco de dados}

A partir dos dados brutos e das primeiras considerações que eles permitem, é possível uma análise mais refinada dos dados. No total, há cerca de 6500 ocorrências de SAY/DIZER no corpus, que podem ser localizadas utilizando-se conjuntamente as ferramentas WordList e Concord do software WordSmith Tools, como foi explicado. Optou-se por selecionar cerca de $10 \%$ das ocorrências e, pensando-se em uma amostragem com o mesmo número de ocorrências de cada romance, optou-se por selecionar as primeiras 50 ocorrências de cada romance, totalizando 599 ocorrências, visto que o número total de ocorrências em um dos romances é 49.

Dado o foco do estudo, os processos verbais, foram eliminadas 30 ocorrências, 04 de SAY e 26 de DIZER, de orações em que SAY/DIZER realizam processos simbólicos e processos relacionais, fugindo, portanto, do escopo da análise.

Cada uma das 599 ocorrências foi analisada na linha de concordância fornecida pela ferramenta Concord e selecionaram-se apenas as ocorrências em que SAY/DIZER realizam processos verbais. Após este recorte, restaram 569 linhas de ocorrências, sendo 296 ocorrências de SAY (149 em textos não-traduzidos (IO) e 147 em textos traduzidos (IT)) e 273 ocorrências de DIZER (132 em textos não-traduzidos (PO) e 141 em textos traduzidos (PT)). 
Estes dados já apontam o fato de que o papel de SAY na realização de orações verbais parece ser mais frequente do que o de DIZER, visto que foram eliminados apenas 04 casos de SAY e 26 casos de DIZER.

O próximo passo foi analisar cada ocorrência em relação às categorias focalizadas. $\mathrm{O}$ início da análise foi feito através de anotação $^{8}$ manual do corpus, que consiste em o pesquisador estabelecer códigos para as categorias analisadas e inserir estes códigos no corpus dentro de etiquetas (denominam-se etiquetas os parênteses angulares $<\mathrm{e}>$, dentro dos quais se insere o código no corpus). Posteriormente, as etiquetas são contabilizadas automaticamente com o programa WordSmith Tools para a obtenção de dados, possibilitando ao pesquisador desenvolver sua análise qualitativa a partir dos dados quantitativos. Entretanto, este processo é bastante limitado para análise de grande quantidade de dados, principalmente quando se utilizam várias categorias. Optou-se, portanto, pelo uso de um programa estatístico, o SPSS (Statistical package for the social sciences).

O programa SPSS trabalha com casos ou ocorrências, variáveis e categorias, formando um banco de dados em uma planilha semelhante às utilizadas pelo programa Excel. O SPSS apresenta muitas facilidades: a construção do banco de dados é simples; é possível classificar separadamente cada aspecto observado e depois cruzar os dados; as ferramentas de geração de tabelas e gráficos são simples e com muitos recursos de produção e edição; estão disponíveis diferentes formas de visualização dos dados. Dentre suas limitações pode-se apontar: custo muito alto do programa; dificuldade para se trabalhar com uma variável que possua mais de cinco categorias; não apresenta nenhuma interface com o texto, visto que o programa não foi desenvolvido especificamente para linguistas; necessidade de conhecimentos de estatística para análises mais elaboradas.

O programa destaca-se pela facilidade de construção de um banco de dados que possibilita o cruzamento de variáveis, a extração de dados de frequência e a geração de tabelas e gráficos, sem aprofundamento em testes estatísticos. Olohan (2004:86) aponta que vários linguistas consideram que os dados de frequência podem ser suficientes para a análise e que os testes de significância não são sempre necessários. A autora cita uma observação de Halliday sobre esse aspecto, em que o autor diz que "dados brutos de frequências geralmente são suficientes para se aceitar a afirmativa do pesquisador de que alguma característica é

\footnotetext{
${ }^{8}$ Confira Feitosa (2005) para um estudo mais detalhado sobre anotação de corpora.
} 
relevante no texto e que se deve verificá-la"9 . Desta forma, o programa foi utilizado para o processamento automático de frequência das variáveis e categorias analisadas com a geração de tabelas e gráficos ${ }^{10}$.

Inicialmente, o pesquisador estabelece as variáveis e categorias de análise que irão fazer parte do banco de dados do SPSS. Recomenda-se a construção de um único banco de dados, portanto, as variáveis e categorias devem englobar todas as ocorrências do corpus. Algumas variáveis podem existir apenas para facilitar a organização do banco de dados, como, por exemplo, a variável OCORRÊNCIAS, que não possui categorias e em que cada número corresponde a uma das 50 linhas de concordância selecionada para investigação em cada romance. Outras variáveis servem para facilitar a seleção de parte dos dados dentro do banco de dados, por exemplo, a variável STATUS cujas categorias são inglês original (IO), português original (PO), inglês traduzido (IT), e português traduzido (PT). O programa permite a seleção de parte dos dados, segundo as diferentes categorias, para a geração de dados, o que permite ao pesquisador, no exemplo da variável STATUS, selecionar os dados em relação às ocorrências de português em geral, ou somente de português traduzido ou somente de português original, segundo os objetivos da pesquisa.

Após vários testes, foram estabelecidas nove variáveis para a análise com suas respectivas categorias, descritas a seguir.

\section{1) Variável: OCORRÊNCIAS. Sem categorias}

Foram selecionadas 300 ocorrências de SAY e 299 ocorrências de DIZER que se constituíram das 50 primeiras ocorrências de cada romance, sendo que um deles possui apenas 49 ocorrências de DIZER. O SPSS conta cada ocorrência como um caso, ocupando uma linha do banco de dados e numerando-as de 1 a 599. Depois de eliminados os 30 casos em que SAY/DIZER não realizam processo verbal, restaram 569 casos. Na variável OCORRENCIA cada uma foi numerada segundo as linhas de concordância selecionadas com o programa WordSmith, ou seja, de 1 a 50 pela ordem de ocorrência.

\footnotetext{
${ }^{9}$ Minha tradução de: "a rough indication of frequencies is often just what is needed: enough to suggest why we should accept the analyst's assertation that some feature is prominent in the text, and allow us to check his statements"(Halliday apud Olohan, 2004:86).

${ }^{10}$ Para exemplos de pesquisas linguísticas com o uso do SPSS, veja a tese de Rothe-Neves (2002) na área de tradução e a dissertação de Oliveira (2006) na área de fonologia da língua portuguesa.
} 
2) Variável: LEXICO. Categorias: SAY e DIZER

Cada ocorrência foi classificada como SAY ou DIZER, conforme faça parte do corpus em português ou do corpus em inglês.

3) Variável: CORPUS. Categorias: os doze romances do corpus combinado

Foi assinalada a origem de cada ocorrência, segundo os doze romances que compõem o corpus combinado. Essa classificação permite que se façam análises separadas de cada romance, procedimento necessário, por exemplo, para a localização de linhas de concordância a serem utilizadas como exemplos. Atribuiu-se uma sigla para cada um, conforme descrito na Tabela 1.

PCP - Point counter point; IWV - Interview with the vampire; BEL - Beloved; MAC - Macunaíma; GAB - Gabriela, clove and cinammon; THS - The hour of the star;

MHS - Macunaíma: o herói sem caráter; GCC - Gabriela, cravo e canela;

AHE - A hora da estrela; CPO - Contraponto; ECV - Entrevista com vampiro;

AMA - Amada

4- Variável: FORMA. Categorias: as formas de SAY/DIZER

Foi analisada a frequência das diferentes formas de SAY/DIZER. Enquanto SAY possui apenas quatro formas, say, says, said, saying, DIZER possui várias, sendo as mais frequentes, disse, dizer, dizia.

5- Variável: MODOPROJ. Categorias: relato, citação, verbiagem

Nesta variável, cada oração verbal foi analisada segundo o modo de projeção: relato ou citação. Os casos classificados como verbiagem indicam que não ocorreu a projeção.

6- Variável: MODOEXP. Categorias: congruente e metáfórico

Cada oração verbal foi classificada segundo o modo de expressão: congruente ou metafórico. As orações de verbiagem não foram analisadas em relação aos modos de expressão. 
7- Variável: TRADUÇÃO. Categorias: traduções de SAY/DIZER no corpus paralelo

Para a classificação desta variável foi necessário realizar antes o alinhamento do corpus paralelo. Alinhar significa colocar um trecho do texto original seguido do trecho do texto traduzido correspondente (Lawson, 2001). Este trabalho foi feito com o auxílio de bolsistas do LETRA e utilizaram-se dois recursos diferentes: a ferramenta Viewer and Aligner do programa WordSmith e o processador de texto Word. O resultado não é muito distinto. O Viewer faz o alinhamento automático, por sentenças ou parágrafos, mas apresenta problemas que precisam ser corrigidos manualmente pelo pesquisador; o texto alinhado pode ser exportado para ser manuseado no Word. No Word, o alinhamento é feito manualmente dividindo-se as sentenças ou parágrafos em duas colunas de uma tabela, uma para o texto original e outra para o texto traduzido.

Então, cada equivalente encontrado passa a ser uma categoria, sendo que esta variável tem tantas categorias quantas forem os possíveis equivalentes, agrupados sob a forma do infinitivo, que funciona como lema. Por exemplo, os itens lexicais mais frequentes correspondentes a SAY no corpus são DIZER, FALAR e RESPONDER. E os mais frequentes correspondentes a DIZER são SAY, TELL e EXPLAIN. Os dados observados nos corpora alinhados foram lançados diretamente no SPSS.

8- Variável: RELAÇÕES. Categorias: prototípico, típico, atípico, omissão e não-verbal

Os itens lexicais que aparecem no corpus em relação de tradução com SAY/DIZER, foram agrupam nestas categorias, segundo o tipo de verbo dentro dos verbos que podem realizar processo verbal.

9- Variável: STATUS. Categorias: inglês/português e original/traduzido

Cada ocorrência foi classificada em relação aos quatro corpora básicos: inglês original (IO), português original (PO), inglês traduzido (IT) e português traduzido (PT).

Todas as 569 ocorrências foram classificadas em relação a estas nove variáveis, formando assim o banco de dados da pesquisa. O SPSS permite que se realize uma análise parcial, excluindo-se uma ou mais variáveis e/ou categorias, facilitando a exploração do banco de dados para diferentes tipos de análise. O programa gera tabelas e gráficos de dados, com extensas possibilidades de edição e apresentação. 
A Figura 1 mostra uma janela do SPSS com as nove variáveis de análise e uma amostra parcial das ocorrências que compõem o banco de dados.

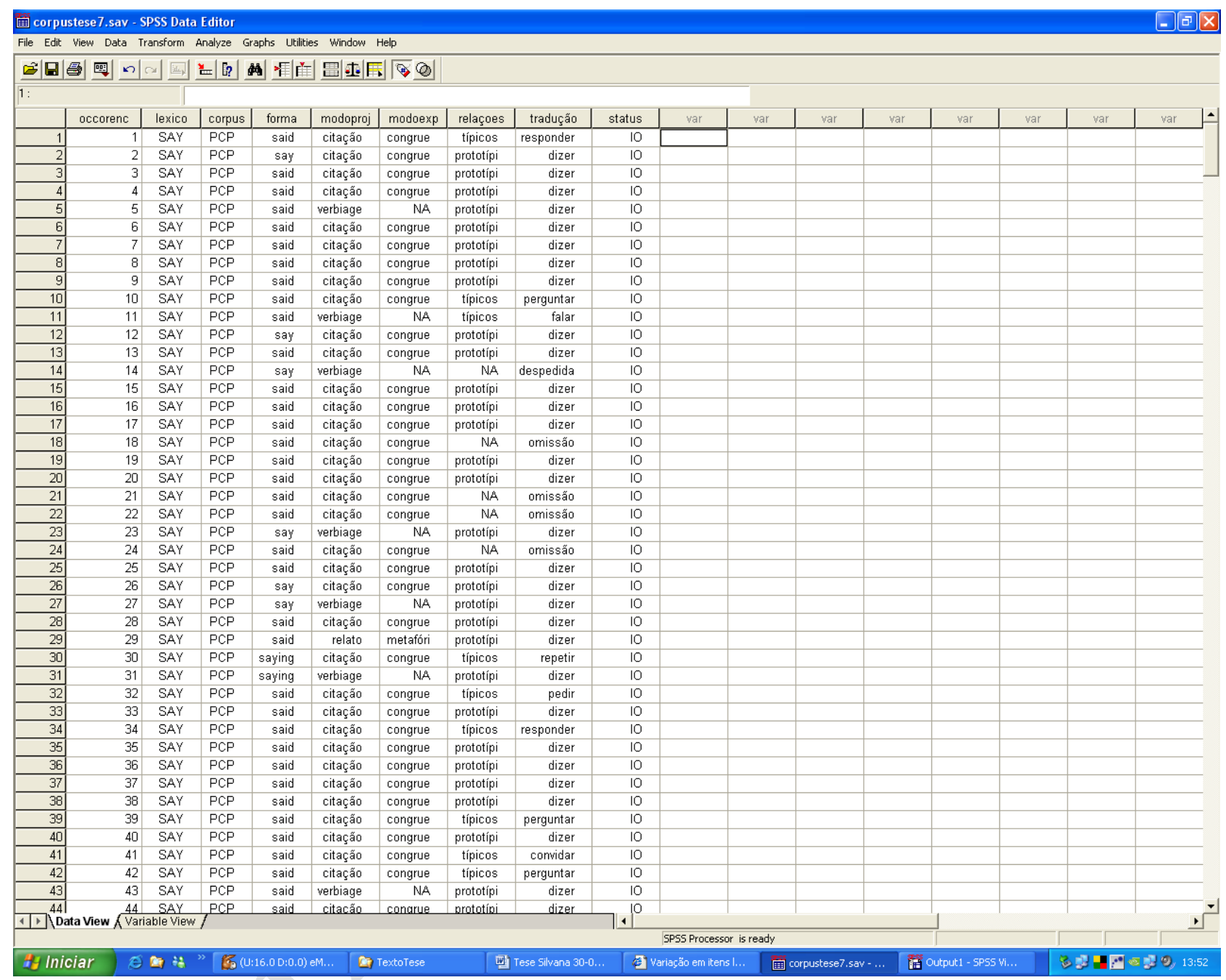

Figura 1 - Janela do programa SPSS com visão parcial do banco de dados

A Tabela 2 é um exemplo de tabela produzida pelo SPSS e mostra as ocorrências de SAY/DIZER nos romances do corpus, abrangendo os quatro corpora básicos do corpus combinado. O corpus de textos originais em inglês (IO) com 149 ocorrências, o corpus de textos originais em português (PO) com 132 ocorrências, o corpus de textos traduzidos em inglês (IT) com 147 ocorrências e o corpus de textos traduzidos em português (PT) com 141 ocorrências, totalizando 569 casos ou ocorrências de SAY/DIZER. Nota-se que as tabelas produzidas pelo SPSS não seguem os padrões da ABNT. 
Tabela 2 - Ocorrências de SAY/DIZER no corpus combinado (exemplo de tabela produzida pelo SPSS)

\section{Romances do corpus * Texto original ou tradução Crosstabulation}

\begin{tabular}{|c|c|c|c|c|c|c|}
\hline & & \multicolumn{4}{|c|}{ Texto original ou tradução } & \multirow[b]{2}{*}{ Total } \\
\hline & & ING nao-trad & POR nao-trad & ING trad & POR trad & \\
\hline \multirow{12}{*}{$\begin{array}{l}\text { Romances } \\
\text { do corpus }\end{array}$} & $\mathrm{PCP}$ & 50 & & & & 50 \\
\hline & IWV & 49 & & & & 49 \\
\hline & BEL & 50 & & & & 50 \\
\hline & MAC & & & 47 & & 47 \\
\hline & GAB & & & 50 & & 50 \\
\hline & THS & & & 50 & & 50 \\
\hline & MHS & & 40 & & & 40 \\
\hline & GCC & & 47 & & & 47 \\
\hline & AHE & & 45 & & & 45 \\
\hline & $\mathrm{CPO}$ & & & & 49 & 49 \\
\hline & ECV & & & & 45 & 45 \\
\hline & AMA & & & & 47 & 47 \\
\hline Total & & 149 & 132 & 147 & 141 & 569 \\
\hline
\end{tabular}

A Tabela 2 está no formato produzido pelo SPSS, mas o programa tem amplos recursos para edição de tabelas. Pode-se, por exemplo, mudar o título, excluir colunas, alterar a fonte, inserir notas, alterar o tamanho e outras edições e formatações, conforme exemplificado na Tabela 3.

Tabela 3 - Exemplo de tabela editada com os recursos do SPSS

Ocorrências de SAYIDIZER nos romances do corpus combinado a

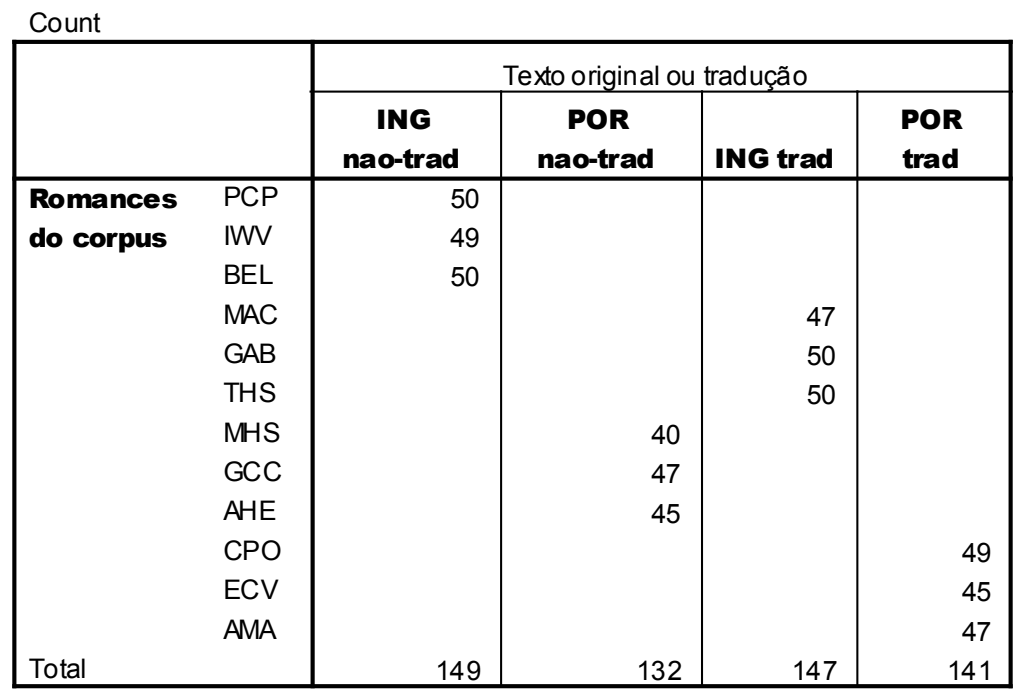

a. Corpus paralelo e comparável bidirecional no par linguístico inglês-português

Além do manual do programa (em inglês), é possível encontrar manuais em português com o passo-a-passo para a utilização dos recursos do programa. 
Todas estas variáveis foram detalhadamente analisadas em Jesus (2008). A próxima seção apresenta, parcialmente, a análise de uma das variáveis, as relações de tradução, para ilustrar a metodologia utilizada.

\section{As relações de tradução entre SAY-DIZER}

O conceito leigo de equivalência geralmente está associado à ideia de que para um determinado item em dada língua A há um item equivalente na língua B. Entretanto, os estudos da tradução desde muito apontam que, para um determinado item em uma língua $\mathrm{A}$, existem vários itens equivalentes na língua B ou, nos termos de Halliday (1992:16), “um item $\mathrm{X}$ na língua do original tem um grupo de itens equivalentes em potencial - A, B, C, D, E, F na língua da tradução" ${ }^{11}$. Portanto, pode-se dizer que existem diferentes relações de tradução entre um item do texto original e seus vários possíveis equivalentes no texto traduzido.

A análise das relações de tradução de SAY/DIZER tem o objetivo de responder as seguintes perguntas: i) Dado que, em dicionários bilíngues, DIZER é o equivalente prototípico de SAY, com qual frequência SAY é traduzido por DIZER? ii) Dado que há ocorrências de SAY que não são traduzidas por DIZER, pois não há apenas um equivalente, quais seriam os possíveis equivalentes de SAY além de DIZER? E qual seria a frequência de ocorrência destes equivalentes? As mesmas perguntas são colocadas em relação em relação a DIZER, pensando-se na direção do português para o inglês.

Considerando-se SAY/DIZER como verbos que realizam Processo verbal, é natural que SAY/DIZER estejam em relações de tradução com outros verbos que também realizam processo verbal. A Gramática sistêmico-funcional (GSF, doravante) (HALLIDAY e MATTHIESSEN 2004) apresenta dois grupos de verbos que realizam processo verbal, segundo o modo de citação e o modo de relato.

Quadro 2 - Verbos que realizam Processo em orações verbais no modo de citação

\begin{tabular}{|c|c|c|}
\hline & Proposição & Proposta \\
\hline (1) Membro geral & SAY & SAY \\
\hline (2)Verbos específicos & Declarações: & (+a) Ofertas: SUGGEST, OFFER; \\
\hline $\begin{array}{l}\text { funções de fala: } \\
\text { a) oferta }\end{array}$ & $\begin{array}{l}\text { receptor), REMARK, } \\
\text { POINT OUT, } \\
\text { ANNOUNCE. }\end{array}$ & $\begin{array}{l}\text { OBSERVE,THREATHEN, } \\
\text { REPORT,PROMISE, AGREE. }\end{array}$ \\
\hline b) demanda & b) Perguntas: ASK, & DEMAND,b) Comandos: CALL, ORDER, \\
\hline
\end{tabular}

\footnotetext{
${ }^{11}$ Minha tradução de: You are aware that an item $\mathrm{X}$ in the source language has a potential equivalence of items
} A, B, C, D, E, F in the target language (Halliday, 1992:16). 


\begin{tabular}{ll}
\hline Proposição & Proposta \\
\hline INQUIRE, QUERY. & REQUEST, TELL, PROPOSE, \\
& DECIDE; URGE, PLEAD, \\
& WARN.
\end{tabular}

(3)Verbos com característicasREPLY, EXPLAIN, PROTEST,[consultar (2) acima] adicionais CONTINUE, ADD, INTERRUPT,

a) circunstanciais WARN.

b)especificadores de modo ouINSIST, COMPLAIN, CRY, [em grande parte como as conotação

SHOUT, BOAST, MURMUR,proposições] BLARE, STAMMER. THUNDER, MOAN, YELL, FUSS.

Fonte: Halliday e Matthiessen (2004:448). Tradução de Alves (2006:29)

A GSF aponta SAY como o membro geral da classe de verbos que realizam processos verbais em citações (Halliday e Matthiessen, 2004:448), conforme apresentado no Quadro 2. Destaca-se seu papel como o membro não-marcado deste grupo de verbos (p. 252). Thompson (1994:34-35) considera SAY como o verbo de elocução básico, utilizado quando não se quer indicar nenhuma finalidade ou modo do dizer, portanto, um verbo neutro. Considera ainda, como neutros, os verbos: tell, ask, write, speak, talk.

Halliday e Matthiessen (2004:448) consideram ainda que outros verbos "que não são verbos de dizer", podem, especialmente na narrativa ficcional, realizar Processos verbais. Os autores destacam os verbos que tipicamente realizam Processos comportamentais (como sob, snort, breathe) e que quando realizam processos verbais expressam atitudes, emoções e gestos que acompanham o ato de fala.

A classificação dos diferentes tipos de verbos que realizam processos verbais é relevante para a análise das relações de tradução de SAY/DIZER, visto que aqueles são os mais prováveis candidatos ao quadro de equivalentes possíveis destes verbos.

Para esta análise, utilizaram-se os corpora paralelos do corpus combinado, compostos de textos originais em inglês (IO) e suas traduções para o português (PT) e de textos originais em português (PO) e suas traduções para o inglês (IT). A análise é bidirecional, ou seja, observa as relações de tradução tanto na direção do português para o inglês, quanto na direção do inglês para o português.

Foram selecionadas as primeiras 50 ocorrências de SAY/DIZER de cada romance. Estas ocorrências foram analisadas, excluindo-se as orações em que SAY/DIZER não realizam processo verbal, como mencionado. Portanto, analisam-se 149 orações verbais realizadas por SAY e 132 orações verbais realizada por DIZER. 
Inicialmente, foram observadas as relações de tradução de SAY/DIZER, considerando-se o estrato léxico-gramatical, ou seja, as relações de equivalência de SAY (em IO) com DIZER e outros itens lexicais do português (em PT) e, por sua vez, as relações de equivalência de DIZER (em PO) com SAY e outros itens lexicais do inglês (em IT).

Ao invés de se considerar isoladamente cada item em relação de tradução com SAY/DIZER, decidiu-se por agrupá-los em categorias semânticas, na perspectiva experiencial de realização de Processos verbais, segundo a classificação da GSF para os diferentes tipos de verbos: i) membro geral, ii) verbos específicos e iii) verbos que, tipicamente, não são verbos de dizer, mas podem realizar esse significado.

Observa-se que, embora não existam descrições do português baseadas na LSF, Neves (2000:48) apresenta uma classificação dos verbos discendi, que se aproxima da proposta da GSF. A autora classifica os verbos de elocução como neutros (dizer e falar), verbos que indicam algum aspecto do dizer, como modo ou cronologia (repetir, gritar, responder) e verbos que podem funcionar como introdutores do discurso (consolar, sorrir). Menciona-se ainda a classificação de Garcia (1986:131), que considera como verbos de elocução os verbos discendi (dizer, perguntar, responder, exclamar) e os verbos sentiendi (gemer, suspirar, lamentar-se, queixar-se), que introduzem o discurso e realizam emoções, atitudes, comportamentos. Utilizou-se, ainda, para a análise dos verbos em português, o Dicionário Houaiss da língua portuguesa ${ }^{12}$, observando-se as significações possíveis para os verbos e suas relações com o universo do dizer. Portanto, utiliza-se uma classificação das relações de tradução de SAY/DIZER em três tipos: i) prototípicos, ii) típicos e iii) atípicos.

Considera-se como prototípico o verbo que é o membro geral da classe, ou seja, SAY/DIZER. E como verbos típicos todos os outros verbos que realizam orações verbais nos modos de citação e relato. Como verbos atípicos consideram-se os verbos que tipicamente realizam outro tipo de Processo (mentais, materiais e outros), mas que nos textos ficcionais geralmente realizam Processos verbais ou que eventualmente podem realizar este tipo de Processo.

Assim, consideram-se três tipos de relações de tradução de SAY e DIZER: i) SAY é traduzido por DIZER, e vice-versa, em que a relação se dá com o verbo prototípico; ii) SAY/DIZER são traduzidos por outros verbos típicos de processos verbais; iii) SAY/DIZER

\footnotetext{
${ }^{12}$ Dicionário online, disponível para assinantes em http://educacao.uol.com.br/dicionarios/ .
} 
são traduzidos por verbos que não são verbos de dizer, mas que podem realizar processo verbal, em que a relação se dá com o verbo atípico.

Ocorrem ainda, no corpus, casos em que SAY/DIZER são traduzidos por um substantivo, ou seja, a relação de tradução não se dá entre verbos. Ou ainda, casos em que a oração verbal realizada por SAY/DIZER é omitida.

Portanto, as relações de tradução de SAY/DIZER encontradas no corpus analisado são classificadas em cinco tipos: prototípico, típico, atípico, não-verbal e omissão. Esta classificação é feita a partir dos corpora paralelos: i) SAY/DIZER aparecem como equivalentes, ou seja, SAY é traduzido por DIZER e DIZER corresponde a SAY, casos classificados como prototípicos; ii) SAY/DIZER são traduzidos por outros verbos que tipicamente realizam Processo verbal como falar, perguntar, responder, pedir, tell, speak, remark, point out, casos classificados como típicos; iii) SAY/DIZER são traduzidos por verbos que tipicamente realizam outros tipos de processos, como lembrar, fazer, mean, think, que são classificados como atípicos; iv) casos em que SAY/DIZER são traduzidos por um substantivo, e v) casos de omissão.

Inicialmente, foram observados os itens lexicais em relação de tradução com SAY no corpus, apresentados na Tabela 4.

Tabela 4 - Itens lexicais em relação de tradução com SAY

\begin{tabular}{|cl|r|r|}
\hline & & Frequency & Valid Percent \\
\hline Valid & dizer & 65,8 \\
& omissão & 21 & 14,1 \\
& falar & 12 & 8,1 \\
& responder & 5 & 3,4 \\
perguntar & 3 & 2,0 \\
não-verbal & 2 & 1,3 \\
comentar & 2 & 1,3 \\
pedir & 1 &, 7 \\
convidar & 1 &, 7 \\
repetir & 1 &, 7 \\
concordar & 1 &, 7 \\
fazer & 1 &, 7 \\
retrucar & 1 &, 7 \\
Total & 149 & 100,0 \\
\hline
\end{tabular}

a. Corpus paralelo inglês-português (IO-PT)

O corpus confirma a expectativa de que DIZER seja o equivalente mais frequente de SAY; a relação com o verbo prototípico ocorre em $65.8 \%$ dos casos. Nota-se que a segunda 
relação mais frequente é a de omissão, que ocorre em 14.1\%. O terceiro item mais frequente foi falar, um dos verbos típicos, que ocorre em $8.1 \%$ dos casos. Há dois casos $(1.3 \%)$ de relação não-verbal. Agrupando-se estes itens lexicais, segundo as categorias de análise, temse outra perspectiva das relações de tradução, apresentadas na Tabela 5.

Tabela 5 - Relações de tradução de SAY segundo as categorias

\begin{tabular}{|ll|r|r|}
\hline & & Frequency & Valid Percent \\
\hline Valid & prototípico & 97 & 65,1 \\
& típicos & 28 & 18,8 \\
& atípicos & 1 &, 7 \\
nao-verbal & 2 & 1,3 \\
omissão & 21 & 14,1 \\
Total & 149 & 100,0 \\
\hline
\end{tabular}

a. Corpus paralelo inglês-português (IO-PT)

O equivalente prototípico ocorre em $65.1 \%$ dos casos, enquanto que verbos típicos de processos verbais ocorrem em $18.8 \%$. Como foi dito, a omissão ocorre em 14.1\% dos casos, há duas ocorrências de relação não-verbal (1.3\%) e uma ocorrência de verbo atípico $(0.7 \%)$. Exemplos do corpus são apresentados no Quadro 3.

Quadro 3 - Exemplos do corpus das relações de tradução de SAY em IO-PT

Prototípico

04 "You forgetting how little it is," said her mother. (BEL)

-- Você está se esquecendo de que ela é muito pequenina, disse a mãe. (AMA)

Típico

45 "But I mean we want to get married."

"You just said so. And I said all right." (BEL)

--O que estou querendo dizer é que vamos nos casar.

-- Já me disse isso. E eu falei que está tudo bem. (AMA)

Atípico

46 'Were you?' said Lady Edward smiling and looking from one to the other. (PCP)

- Estavam? - fez Lady Edward, sorridente, olhando ora para uma ora para outra. (CPO)

Omissão

17 "We and Denver," she said.

"That all right by you? (BEL)

-- Eu e Denver.

-- E está tudo bem com você? (AMA)

Não-verbal

14 When the time came to say good-bye, he had shaken the skeleton hand. (PCP)

Chegara o momento da despedida: ele apertou na sua a mão esquelética do doente, a mão que jazia inerte sobre a coberta. (CPO) 
08 She had not thought to ask him and it bothered her still that it might have been possible-that for twenty minutes, a half hour, say, she could have had the whole thing, every word she heard the preacher say at the funeral (and all there was to say, surely) engraved on her baby's headstone: Dearly Beloved. (BEL)

Não pensara em perguntar-lhe e ainda se perturbava com a probabilidade de ter sido possível - que por vinte minutos, talvez meia hora, teria obtido a coisa inteira, cada palavra que ouvira o pastor dizer no funeral (e certamente tudo o que havia para ser dito) gravada na lápide de sua filhinha: Caríssima Amada. (AMA)

\section{Exemplos do corpus paralelo: inglês original (IO) e português traduzido (PT)}

Em seguida, observaram-se os itens lexicais em relação de equivalência com DIZER, apresentados na Tabela 6.

Tabela 6 - Itens lexicais em relação de tradução com DIZER

\begin{tabular}{|c|c|c|c|}
\hline & & Frequency & Valid Percent \\
\hline \multirow[t]{39}{*}{ Valid } & saya & 61 & 46,2 \\
\hline & tell & 14 & 10,6 \\
\hline & omissão & 8 & 6,1 \\
\hline & mention & 4 & 3,0 \\
\hline & explain & 4 & 3,0 \\
\hline & não-verbal & 3 & 2,3 \\
\hline & speak & 3 & 2,3 \\
\hline & think & 3 & 2,3 \\
\hline & mutter & 2 & 1,5 \\
\hline & ask & 2 & 1,5 \\
\hline & laugh & 1 & ,8 \\
\hline & insist & 1 & ,8 \\
\hline & believe & 1 & , 8 \\
\hline & conclude & 1 & ,8 \\
\hline & pronounce & 1 & ,8 \\
\hline & divulge & 1 & ,8 \\
\hline & inform & 1 & 8 \\
\hline & snap & 1 & ,8 \\
\hline & retort & 1 & ,8 \\
\hline & observe & 1 & ,8 \\
\hline & call & 1 & ,8 \\
\hline & remark & 1 & ,8 \\
\hline & confide & 1 & ,8 \\
\hline & object & 1 & ,8 \\
\hline & comment & 1 & 8 \\
\hline & express & 1 & ,8 \\
\hline & beg & 1 & ,8 \\
\hline & rejoin & 1 & 8 \\
\hline & reply & 1 & ,8 \\
\hline & hear & 1 & ,8 \\
\hline & add & 1 & 8 \\
\hline & go & 1 & 8 \\
\hline & res ume & 1 & 8 \\
\hline & accuse & 1 & ,8 \\
\hline & find & 1 & 8 \\
\hline & concede & 1 & ,8 \\
\hline & cover & 1 & ,8 \\
\hline & imagine & 1 & ,8 \\
\hline & Total & 132 & 100,0 \\
\hline
\end{tabular}

a. Corpus paralelo português-inglês (PO-IT) 
DIZER se destaca como o equivalente prototípico de SAY, embora não chegue a $50 \%$ dos casos (46.2\%). O segundo item mais frequente é tell, com 10.6\%. A porcentagem de omissão de DIZER é de $6.1 \%$ e há três ocorrências de relação não-verbal (2.3\%). A Tabela 7 mostra as relações de tradução de DIZER, quando se agrupam estes itens segundo as categorias de análise.

Tabela 7 - Relações de tradução de DIZER segundo as categorias

\begin{tabular}{|ll|r|r|}
\hline & & Frequency & Valid Percent \\
\hline Valid & prototípico & 61 & 46,2 \\
& típicos & 49 & 37,1 \\
& atípicos & 11 & 8,3 \\
nao-verbal & 3 & 2,3 \\
omissão & 8 & 6,1 \\
Total & 132 & 100,0 \\
\hline
\end{tabular}

a. Corpus paralelo português-inglês (PO-IT)

O equivalente prototípico ocorre em $46.2 \%$ dos casos, enquanto que outros verbos típicos de processos verbais ocorrem em $37.1 \%$ e verbos atípicos em $8.3 \%$. A omissão ocorre em $6.1 \%$ e a relação não-verbal em 2.3\%. Exemplos no Quadro 4.

Quadro 4 - Exemplos do corpus das relações de tradução de DIZER em PO-IT

Prototípico

17 -- Isso é revoltante - dizia o Doutor enquanto o grupo caminhava pela rua sem calçamento, contornando o morro. (GCC)

"This is revolting," said the Doctor as the group walked along the unpaved street skirting the hill.

Típico

$37 \mathrm{O}$ ticotiquinho ficava azaranzado porque estava padecendo fome e aquele nhenhenhém-nhenhenhém azucrinando ele atrás, diz-que "Telo decumê!... telo decumê!..." (MHS)

The cowbird swallowed everything and resumed its habitual refrain "Boo-hoo! Mama, I'm famished, I'm famished!" (MAC)

\section{Atípico}

$32 \mathrm{E}$ todos com muito medo foram correndo pra dentro. Então Chuvisco desapeou e disse pra Macunaíma: Está vendo? (MHS)

Shower came down and laughed at Macunaíma: "Did you see that?" (MAC)

Omissão

12 Em Itamaracá Macunaíma passou um pouco folgado e teve tempo de comer uma dúzia de manga-jasmim que nasceu do corpo de dona Sancha, dizem. (MHS)

They ran to the island of Itamaracá, where the hero ate some mangoes, a dozen jasmin mangoes that had sprung from the grave of the late Dona Sancha; (MAC) 
$03 \mathrm{O}$ seu rico andor bordado de ouro, levavam-no sobre os ombros orgulhosos os cidadãos mais notáveis, os maiores fazendeiros, vestidos com a bata vermelha da confraria, e não é pouco dizer, pois os coronéis do cacau não primavam pela religiosidade... (GCC)

The gold-embroidered litter bearing the image of the saint was carried on the shoulders of the town's most important citizens, the owners of the largest plantations, dressed in the red gowns of the lay brotherhood. This was significant, for the cacao colonels ordinarily avoided religious functions. (GAB)

21 Pelópidas de Assunção d'Ávila descendia de uns Ávilas, fidalgos portugueses estabelecidos nas bandas de Ilhéus ainda no tempo das capitanias. Pelo menos assim o afirmava o Doutor, dizendo-se baseado em documentos de família. Opinião ponderável, de historiador. Descendente desses celebrados Ávilas, cujo solar elevara-se entre Ilhéus e Olivença, hoje negras ruínas ante o mar, cercadas de coqueiros, mas também de uns Assunções plebeus e comerciantes - diga-se em sua homenagem, ele cultuava a memória de uns e de outros com o mesmo fervor exaltado. (GCC)

Pelópidas de Assunção d'Ávila (the Doctor) maintained that he was descended from the Portuguese noblemen named Ávila who had settled near what was now Ilhéus during the period of royal land grants. The line of descent could be clearly traced, he found, in family documents. The solid opinion of a historian. He was descended also from certain plebeian, shopkeeping Assunções, and, to his great credit, he cherished the memory of these ancestors and of the Ávilas with the same exalted fervor. (GAB)

$01 \mathrm{Si}$ o incitavam a falar exclamava:

- Ai! que preguiça!...

e não dizia mais nada. (MHS)

If anyone tried to make him speak he would exclaim, "Aw! What a fucking life!" but nothing more.

Exemplos do corpus paralelo: português original (PO) e inglês traduzido (IT)

Vários aspectos se destacam nas relações de tradução de SAY e DIZER a partir destes dados do corpus. Poder-se-ia pensar que SAY é a tradução de DIZER na mesma proporção que DIZER é a tradução de SAY, mas os dados apontam diferenças nas relações de tradução, conforme a direção seja do inglês para o português ou do português para o inglês. Estas diferenças são discutidas em cada uma das relações de tradução observadas para SAY e DIZER.

Relação de tradução I - equivalente prototípico

A ocorrência do equivalente prototípico é maior na direção do inglês para o português $(65.1 \%)$ do que do português para o inglês $(46.2 \%)$.

Relação de tradução II - equivalente típico

SAY apresenta relações de tradução com 09 verbos típicos de Processos verbais no português além de DIZER: falar, responder, perguntar, comentar, pedir, convidar, repetir, concordar e retrucar. DIZER, por sua vez, aparece em relação de tradução com 26 verbos típicos de Processos verbais além de SAY: tell, mention, explain, speak, mutter, ask, insist, pronounce, divulge, inform, snap, retort, observe, call, remark, confide, object, comment, 
express, beg, rejoin, reply, add, resume, accuse e concede. Estatisticamente, $18.8 \%$ das ocorrências de SAY estão em relação de tradução com verbos típicos e 37.1\% das ocorrências de DIZER.

Relação de tradução III - equivalente atípico

SAY apresenta relação de tradução com 01 verbo atípico (fazer), ao passo que DIZER apresenta relações de tradução com 09 verbos atípicos: think, laugh, conclude, believe, hear, go, find, cover e imagine. Este tipo de relação representa $0.7 \%$ das ocorrências com SAY e $8.3 \%$ das ocorrências com DIZER.

Relação de tradução IV - equivalente não-verbal

Há 02 casos com SAY (1.3\%) e 03 com DIZER (2.3\%).

Relação de tradução V - omissão

A omissão ocorre $14.1 \%$ com SAY e $6.1 \%$ com DIZER.

\section{Apontamentos finais}

Este artigo analisou as relações de tradução de SAY/DIZER a partir do uso de um corpus combinado. Foram observados os equivalentes possíveis destes itens, a partir dos correspondentes encontrados no corpus. Apresentou-se, ainda, a metodologia da pesquisa e os primeiros passos da análise, visto que a metodologia não se desenvolve de forma linear, mas vai sendo construída a partir das primeiras etapas da pesquisa em análises piloto. Discutiu-se a terminologia utilizada para classificação dos diferentes tipos de corpus, observando-se que o corpus combinado oferece uma maior abrangência de possibilidades de pesquisa, permitindo ao pesquisador ampliar as perspectivas de análise. Foram descritas as características de um corpus combinado, bem como os procedimentos metodológicos para extração de dados. Foram introduzidos os programas computacionais WordSmith Tools e SPSS e as variáveis e categorias que podem ser usadas para pesquisa com estes programas. Mostrou-se como iniciar a pesquisa a partir dos dados brutos, que possibilitam ao pesquisador as primeiras observações a partir das quais a análise pode desenvolver-se. Desta forma, o trabalho ilustra a produtividade do uso de corpus combinado nos Estudos da tradução baseados em corpora. 


\section{Referências bibliográficas}

ALVES, D. A. S. Aspectos da representação do discurso em textos traduzidos: os verbos de elocução neutros. 2006. Dissertação (Mestrado em Estudos Linguíticos). Faculdade de Letras, Universidade Federal de Minas Gerais.

ALVES, D. A. S.; MORINAKA, E. M. Compilação de procedimentos metodológicos adotados por pesquisadores(as) em Estudos da Tradução e interfaces com as Linguísticas Sistêmico-Funcional e de Corpus. Disponível em < www.geocities.com/xalaskero/UFMG/Metodologia $>$. Acesso em $<15$ junho $2007>$.

ASSIS, R. C. A transitividade na representação de Sethe no corpus paralelo "BelovedAmada". 2004. Dissertação (Mestrado em Estudos Linguísticos). Faculdade de Letras, Universidade Federal de Minas Gerais.

BAKER, M. Corpus linguistics and translation studies: implications and applications. In: BAKER et al. (Ed.). Text and technology: in honour of John Sinclair. Amsterdam/Philadelphia: John Benjamins Publishing Company, 1993. Cap., p. 233-250.

BAKER, M. Corpora in translation studies: an overview and some suggestions for future research. Target, Amsterdam, v. 7, n. 2, p. 223-243, 1995 . crossref http://dx.doi.org/10.1075/target.7.2.03bak

BAKER, M. Corpus-based translation studies: the challenges that lie ahead. In: SOMERS, H. (Ed.). Terminology, LSP and translation: studies in language engineering in honour of Juan C. Sager. Amsterdam/Philadelphia: John Benjamins Publishing Company, 1996. Cap., p. 177186.

BERBER SARDINHA, T. Linguística de corpus. Barueri, SP: Manole, 2004.

BUENO, L. T. Transitividade, coesão e criatividade lexical em "Macunaíma", de Andrade, e "Macunaíma", de Goodland. 2005. Dissertação (Mestrado em Estudos Linguísticos). Faculdade de Letras, Universidade Federal de Minas Gerais.

CANÇADO, T. Transitividade e representação do discurso no corpus paralelo "Interview with the Vampire/Entrevista com o Vampiro". 2005. Dissertação (Mestrado em Estudos Linguísticos). Faculdade de Letras, Universidade Federal de Minas Gerais.

DAYRELL, C. Investigating lexical patterning in translated Brazilian Portuguese: a corpus-based study. 2005. 316 p. Tese (Doutorado em Estudos da Tradução). Centre for Translation and Intercultural Studies, The University of Manchester.

FEITOSA, M. P. Uma proposta de anotação de corpora paralelos com base na linguística sistêmico-funcional. 2005. Dissertação (Mestrado em Estudos Linguísticos). Faculdade de Letras, Universidade Federal de Minas Gerais.

FRANKENBERG-GARCIA, A. Corpora e Tradução. Disponível em < http://www.linguateca.pt/escolaverao2006/ > . Acesso em $<15$ junho $2007>$. 
GARCIA, O. M. Comunicação em prosa moderna. 13. ed. Rio de Janeiro: Fundação Getúlio Vargas, 1986.

HALLIDAY, M.A.K. Language theory and translation practice. Rivista internazionale di tecnica della traduzione, Triesta, n. 1 (pilot issue), p. 15-25, 1992.

HALLIDAY, M.A.K.; MATTHIESSEN, C. M. I. M. An introduction to functional grammar. 3rd edition, rev. ampl. London: Arnold, 2004. 689 p.

HANSEN, S.; TEICH, E. Multi-layer analysis of translation corpora: methodological issues and practical implications. In: EUROLAN 2001: Workshop on Multi-layer Corpus-based Analysis, 2001, Proceedings... Disponível em $<$ http://www.coli.unisaarland.de/publications/show.php?year $=2001>$, Acesso em $<$ janeiro de $2008>$.

HANSEN, S. The nature of translated text: an interdisciplinary methodology for the investigation of the specific properties of translations. 2002. 245 p. Tese (Doutorado em Estudos da Tradução). Department of Applied Linguistics, Saarland University. (Saarbrucken dissertations in computational linguistics and language technology, v. 13).

JESUS, S. M.. Representação do discurso e tradução: padrões de textualização em corpora paralelo e comparável. 2004. 128 p. Dissertação (Mestrado em Estudos Linguísticos). Faculdade de Letras, Universidade Federal de Minas Gerais.

JESUS, S. M. Relações de tradução: SAY e DIZER em corpora de textos ficcionais. 2008. Tese (Doutorado em Linguística Aplicada). Faculdade de Letras, Universidade Federal de Minas Gerais.

JOHANSSON, S. On the role of corpora in cross-linguistic research. In: JOHANSSON, S; OKSEFJELL, S. (Ed). Corpora and cross-linguistic research: theory, method, and case studies. Amsterdam: Rodopi, 1998. Cap. 1, p. 3-24.

JOHANSSON, S.; OKSEFJELL, S. (Ed). Corpora and cross-linguistic research: theory, method, and case studies. Amsterdam: Rodopi, 1998. 376 p. (Language and computers: studies in practical linguistics, n. 24)

LAWSON, A. Collecting, aligning and analyzing parallel corpora. In: GHADESSY, M. et al. (Ed.). Small corpus studies and ELT. Theory and practice. Amsterdam: John Benjamins, 2001. Cap., p. 47-67.

MORINAKA, E. M. "Gabriela, cravo e canela" and its (re)textualization in English: representation through lexical relations. 2005. Dissertação (Mestrado em Estudos Linguísticos). Faculdade de Letras, Universidade Federal de Minas Gerais.

NEVES, M. H. de M. A gramática funcional. São Paulo: Martins Fontes, 1997. (Coleção Texto e Linguagem).

NEVES, M. H. de M. Gramática de usos do português. São Paulo: UNESP, 2000: 31-53. 
OLIVEIRA, A. J. Variação em itens lexicais terminados em /l/+vogal na região de Itaúna/MG. 2006. Dissertação (Mestrado em Estudos Linguísticos). Faculdade de Letras, Universidade Federal de Minas Gerais.

OLOHAN, M. Introducing corpora in Translation Studies. London: Routledge, 2004. 220 p.

RODRIGUES, R. R. A organização temática em "A hora da estrela" $e$ "The hour of the star": um estudo de caso. 2005. Dissertação (Mestrado em Estudos Linguísticos). Faculdade de Letras, Universidade Federal de Minas Gerais.

ROTHE-NEVES, R. Características cognitivas e desempenho em tradução: investigação em tempo real. 2002. Tese (Doutorado em Estudos Linguísticos). Faculdade de Letras, Universidade Federal de Minas Gerais.

SCOTT, M. WordSmith Tools. 1999. Disponível em < http://www.lexically.net/wordsmith/ >Acesso em: 12 março 2003.

TAGNIN, S. E. O. (Org). Cadernos de Tradução IX (Número especial sobre Tradução e Corpora). Florianópolis: UFSC/NUT, 2002, n. 1, 278 p.

TAGNIN, S. E. O. Os corpora: instrumentos de auto-ajuda para o tradutor. Cadernos de Tradução IX, Tradução e Corpora. Florianópolis, 2002a, n. 1, p. 191-219.

TEICH, E. Towards a model for the description of cross-linguistic divergence and commonality in translation. In: STEINER, E.; YALLOP, C. (Ed.). Exploring translation and multilingual text production: beyond content. Berlin, New York: Mouton de Gruyter, 2001. Cap, p. 191-227.

TEICH, E. Cross-linguistic variation in system and text: a methodology for the investigation of translations and comparable texts. Berlin: Mouton de Gruyter, 2003. 276p. (Text, translation, computational processing, 5). crossref http://dx.doi.org/10.1515/9783110896541

THOMPSON, G. Collins Cobuild English Guides 5: Reporting. London: HarperCollins Publishers, 1994.

TOURY, G. Descriptive translation studies and beyond. Amsterdam: John Benjamins, 1995. 311 p. (Benjamins Translation Library).

VELA, M; HANSEN-SCHIRRA, S. The use of multi-level annotation and alignment for the translator. In: ASLIB Translating and the computer 28 conference, 2006, Londres. Proceedings.... Disponível em $<$ http://fr46.uni-saarland.de/croco/publication_en.html $>$ Acesso em $<14$ junho $2007>$

\section{Corpus analisado}

AMADO, J. Gabriela, cravo e canela. Rio de Janeiro: Record, 1958. 
AMADO, J. Gabriela, clove and cinnamon. Trad. Taylor, J. e Grossman . New York: Avon Books, 1962. (Tradução de Gabriela, cravo e canela).

ANDRADE, M. Macunaíma: o herói sem nenhum caráter. São Paulo e Belo Horizonte: Martins e Itatiaia, 1980.

ANDRADE, M. Macunaíma. Tradução de E. A. Goodland. London: Quartet Books, 1984. (Tradução de: Macunaíma: o herói sem caráter).

HUXLEY, A. Point counter point. London: Flamingo, 1994. (Coleção Modern Classic).

HUXLEY, A. Contraponto. Trad. Érico Veríssimo. Porto Alegre: Editora Globo, 1971. (Tradução de: Point counter point - Coleção Imortais da Literatura).

LISPECTOR, C. A hora da estrela. Rio de Janeiro: Rocco, 1998.

LISPECTOR, C. The hour of the star. Trad. Giovanni Pontiero. New York: New Directions Books, 1992. (Tradução de $A$ hora da estrela).

MORRISON, T. Beloved . New York: Alfred A. Knopf, 1998. 275p.

MORRISON, T. Amada. Tradução de Evelyn Kay Massaro. São Paulo: Ed. Best Seller, 1987. 321p. (Tradução de: Beloved).

RICE, A. Interview with the vampire. New York: Ed. Ballantine Books, 1997.

RICE, A. Entrevista com o vampiro. Trad. Clarice Lispector. Rio de Janeiro: Rocco, 1996. (Tradução de: Interview with the vampire).

Artigo recebido em: 15.10 .2014

Artigo aprovado em: 25.11.2014 